\title{
The psychological impact of COVID-19 pandemic on Pakistani population: Managing challenges through mental health services
}

\author{
Khunsa Junaid ${ }^{*}$, Hassan $\mathrm{Ali}^{2}$ and Maryam Khalid ${ }^{3}$ \\ ${ }^{1}$ Department of Community Medicine, King Edward Medical University, Lahore, Pakistan \\ ${ }^{2}$ Department of Public Health, University of Punjab, Lahore, Pakistan \\ ${ }^{3}$ Department of Social Work, University of Punjab, Lahore, Pakistan
}

\section{Communication}

The Novel Coronavirus which causes COVID-19 is the ongoing global public health emergency and the greatest challenge we are facing nowadays. Wuhan, Hubei, China was the place where this disease was first recognized in December 2019. On March 11, 2020, this disease was declared a pandemic by World Health Organization (WHO). It also has been announced as a Public Health Emergency of International Concern on January 30, 2020 by World Health Organization (WHO) [1]. As of $15^{\text {th }}$ May 2020, the novel Coronavirus has affected more than $4,527,165$ people around the world and has taken more than 303,416 lives and has spread to more than 210 countries and territories. By February 2020, the Coronavirus was confirmed to have reached in Pakistan and there were 37218 total cases, 10,155 recoveries and 803 deaths as of $15^{\text {th }}$ May 2020 [2]. In order to control this situation, the Government of Pakistan has issued a series of national and provincial guidelines such as limiting travel, social distancing, strict quarantine measures and closure of educational institutes all over the country and these guidelines have been disseminated on various channels successfully [3].

The psychological impact of the Covid-19 is mainly ignored because most of the researchers all over the world are working hard for an effective vaccine as well as effective treatment for this illness. During a pandemic like Covid-19; not only the health of people is affected; it may have an effect on living conditions of the people causing social malfunction. The seriousness of the condition, uncertainty about the control of the disease and misinformation are some of the most worrisome situations that can increase anxiety among masses [4]. Major preoccupations, for instance fear of death, feelings of solitude and annoyance, stigma, mass hysteria, panic and xenophobia and common mental disorder like anxiety and depression can occur among masses especially among those who are quarantined [5].

In addition to the health of general population, COVID-19 pandemic can affect the frontline health care workers as well as people having mental health illness which may cause a relapse or intensification of a previously existing mental health condition. The likely reasons in these patients may be prison-like conditions in psychiatric wards, little awareness of risks, fewer efforts concerning personal safety, lack of insight in patients, hurdles in approaching health services on time due to discrimination and inequity related to mental ill health in health care settings. The treatment becomes even more demanding and possibly less effective with both illnesses; mental health illness and COVID-19 and the regular out-patient visits for assessment and prescription become more difficult to attend due to nationwide restriction on travel and quarantine regulations [6].

It appears that, besides the efforts at different levels in order to combat the illness outbreak and troublesome conditions, particular importance should be given to the mental health problems of the community and patients. Health authorities should recognize the health care groups and communities who are at high risk of psychological distress due to deprivation of psycho-social and emotional support from their families and home countries; thus demanding more practical and emotional support. Mental wellness and psychological interventions like Cognitive Behavior Therapy (CBT) and Mindfulness-Based Therapy (MBT) should be provided online or via smart- phone based psychoeducation. Organizations should support their staff by shortening the working hours, frequent rest periods and rotating the shifts for those working in high risk areas. Both healthcare authorities and government should provide verified health information and pragmatic tips to public on how to react during pandemics and how they can emotionally deal with their fears and uncertainties associated with the infection. It is a necessity of time to integrate and combine all resources to prepare a more coordinated and comprehensive mental health service delivery to all people. The community psychiatric partners like Social Service Agencies (SSA) should provide counseling during this pandemic. It helps to build up mental health resilience of a community. It also lessens the probability of developing negative psychological impact on the nation.

\section{References}

1. World Health Organization (2020) Statement on the second meeting of the International Health Regulations (2005) Emergency Committee regarding the outbreak of novel Coronavirus (2019-nCoV).

2. Worldmeter.Covid-19 Coronavirus.

3. Ministry of national health services, regulations and coordination of Pakistan (2020) National action plan for corona virus diseases (Covid-19) Pakistan. Government of Pakistan.

4. Duan L, Zhu G (2020) Psychological interventions for people affected by the COVID-19 epidemic. Lancet Psychiatry 7: 300-302.

${ }^{\star}$ Correspondence to: Khunsa Junaid, Department of Community Medicine, King Edward Medical University, Lahore 75500, Pakistan, E-mail khunsajunaidmir@gmail.com

Received: May 15, 2020; Accepted: May 22, 2020; Published: May 28, 2020 
Junaid K (2020) The psychological impact of COVID-19 pandemic on Pakistani population: Managing challenges through mental health services

5. Zhang J, Wu W, Zhao X, Zhang W (2020) Recommended psychological crisis intervention response to the 2019 novel corona virus pneumonia outbreak in China: A model of West China Hospital. Precis Clin Med 1:1-6.
6. Sartorius N (2013) Comorbidity of mental and physical diseases: A main challenge for medicine of the 21st century. Shanghai Arch Psychiatry 25: 68-69.

Copyright: ( 02020 Junaid K. This is an open-access article distributed under the terms of the Creative Commons Attribution License, which permits unrestricted use, distribution, and reproduction in any medium, provided the original author and source are credited. 